\title{
A Fatal Case of Traumatic Brain Injury With Severe Coagulopathy Due to Rhabdophis Tigrinus (Yamakagashi) Bites, A Case Report
}

Daisuke Ueno ( $\sim$ daisuke0111@hotmail.co.jp )

Kawasaki Medical School: Kawasaki lka Daigaku https://orcid.org/0000-0003-2790-5363

\section{Yasukazu Shiino}

Kawasaki Medical School: Kawasaki Ika Daigaku

Jiro Takahashi

Kawasaki Medical School: Kawasaki Ika Daigaku

Satomi Miyamoto

Kawasaki Medical School: Kawasaki Ika Daigaku

\section{Takahiro Inoue}

Kawasaki Medical School: Kawasaki Ika Daigaku

\section{Case report}

Keywords: recombinant thrombomodulin, disseminated with a fibrinolytic phenotype, antivenom

Posted Date: April 9th, 2021

DOI: https://doi.org/10.21203/rs.3.rs-401396/v1

License: (9) This work is licensed under a Creative Commons Attribution 4.0 International License. Read Full License

Version of Record: A version of this preprint was published at International Journal of Emergency Medicine on December 1st, 2021. See the published version at https://doi.org/10.1186/s12245-02100402-4. 


\section{Abstract \\ Background}

Yamakagashi venom is a prothrombin activator, leading to disseminated intravascular coagulation. We report a fatal case of severe coagulopathy from head trauma assumed to be caused by a yamakagashi bite.

\section{Case Presentation:}

An 80-year-old man fell and developed systemic tonic-clonic convulsions. Head computed tomography revealed brain contusion and acute subdural hematoma. Physical examination revealed two bite marks with persistent bleeding on the right lower leg. The patient stated that he had been bitten by some creature 3 days prior, but the bite was left untreated. Laboratory tests showed fibrinogen levels below the detection limit. Even though 18 units of fresh frozen plasma were administered for coagulopathy, fibrinogen levels did not improve. He died approximately 13 hours after admission.

\section{Conclusion}

In this case of a yamakagashi bite with active bleeding due to trauma, early administration of Yamakagashi antivenom should be considered to control coagulopathy.

\section{Background}

Although the exact number is still unknown, there have been 37 cases in 40 years, making these cases relatively rare. ${ }^{1}$ Only one fatal case has been reported since 2000 due to the early administration of yamakagashi antivenom in severe cases. Here, we report a fatal case of severe coagulopathy from head trauma assumed to be caused by a yamakagashi bite.

\section{Case Presentation}

An 80-year-old man visited a neighboring hospital complaining of back pain. He accidentally fell in the waiting room and subsequently developed systemic tonic-clonic convulsions. Head computed tomography (CT) revealed a single cerebral contusion in the left frontal lobe and a left subacute subdural hematoma (Fig. 1A), and the patient was transferred to our hospital. His vital signs appeared normal; however, mild disturbance of consciousness was observed (Glasgow Coma Scale E4V4M6). The light reflex was prompt on both sides and there was no anisocoria. Physical examination revealed two swollen and continuously bleeding bite marks on the right lower leg (Fig. 2). The patient stated that he had been bitten by a creature 3 days prior and left his bite untreated. No other physical or trauma-related changes were observed, and no abnormalities except coagulopathy were noted on laboratory tests (Table 1). The 
patient showed a prolonged prothrombin and activated partial thromboplastin time, and fibrinogen levels were below the detection limit. Follow-up head CT revealed a single brain contusion and a small amount of acute subdural hematoma in the left frontal lobe (Fig. 1B). Accordingly, the patient was diagnosed with a head injury accompanied by severe coagulopathy and admitted to the intensive care unit. The neurosurgeon found no indications for surgery. For coagulopathy, 18 units of fresh frozen plasma (FFP) were administered $\sim 8$ hours after admission, but fibrinogen levels showed little improvement (Fig. 1). Head CT performed 7 hours after the injury revealed gradual worsening of intracranial hemorrhage (Fig. 1C). Furthermore, his state of consciousness deteriorated over time. However, surgical intervention was not indicated because of severe coagulopathy. The patient died 3 days after the bite, approximately 13 hours after hospital admission. 
Table 1

Laboratory examination results on arrival at our hospital

\begin{tabular}{|c|c|c|c|c|c|c|c|c|}
\hline WBC & 6840 & $/ \mu \mathrm{L}$ & TP & 6.6 & $g / d L$ & $\mathrm{Na}$ & 142 & $\mathrm{mEq} / \mathrm{L}$ \\
\hline Neut & 78.4 & $\%$ & Glu & 132 & $\mathrm{mg} / \mathrm{dL}$ & K & 3.9 & $\mathrm{mEq} / \mathrm{L}$ \\
\hline Mono & 5.8 & $\%$ & T-Bil & 1.5 & $\mathrm{mg} / \mathrm{dL}$ & $\mathrm{Cl}$ & 109 & $\mathrm{mEq} / \mathrm{L}$ \\
\hline Eos & 0.3 & $\%$ & ALP & 77 & IU/L & & & \\
\hline \multirow[t]{2}{*}{ Lym } & 15.1 & $\%$ & T-cho & 197 & $\mathrm{mg} / \mathrm{dL}$ & BGA & & \\
\hline & & & & & & (room air) & & \\
\hline Baso & 0.4 & $\%$ & Y-GTP & 26 & IU/L & $\mathrm{pH}$ & 7.404 & \\
\hline RBC & $442 \times 10^{4}$ & $/ \mu \mathrm{L}$ & LDH & 245 & IU/L & $\mathrm{PaO} 2$ & 84.7 & $\mathrm{mmHg}$ \\
\hline $\mathrm{Hb}$ & 13.9 & $\mathrm{~g} / \mathrm{dL}$ & Alb & 4.3 & $\mathrm{~g} / \mathrm{dL}$ & $\mathrm{PaCO} 2$ & 38.0 & $\mathrm{mmHg}$ \\
\hline $\mathrm{Ht}$ & 39.2 & $\%$ & Glb & 2.3 & $\mathrm{~g} / \mathrm{dL}$ & BE & -1.2 & $\mathrm{mmol} / \mathrm{L}$ \\
\hline \multirow[t]{2}{*}{ Plt } & $11.0 \times 10^{4}$ & $/ \mu \mathrm{L}$ & ChE & 256 & IU/L & Lac & 1.14 & $\mathrm{mmol} / \mathrm{L}$ \\
\hline & & & AST & 21 & IU/L & & & \\
\hline PT-INR & 2.12 & & ALT & 14 & IU/L & & & \\
\hline APTT & $>100$ & $\mathrm{sec}$ & $\mathrm{Cr}$ & 0.64 & $\mathrm{mg} / \mathrm{L}$ & & & \\
\hline Fib & $<50$ & $\mathrm{mg} / \mathrm{dL}$ & BUN & 30 & $\mathrm{mg} / \mathrm{dL}$ & & & \\
\hline D dimer & 112.0 & $\mu \mathrm{g} / \mathrm{mL}$ & CRP & 0.10 & $\mathrm{mg} / \mathrm{dL}$ & & & \\
\hline \multicolumn{9}{|c|}{$\begin{array}{l}\text { WBC, white blood cell; Neut, neutrophil; Mono, monocyte; Eos, eosinophil; Lym, lymphocyte; Baso, } \\
\text { basophil; RBC, red blood cells; Hb, hemoglobin; Ht, hematocrit; Plt, platelet; PT-INR, Prothrombin Time-- } \\
\text { International Normalized Ratio; APTT, activated partial thromboplastin time; Fib, Fibrinogen; TP, Total } \\
\text { protein; Glu, glucose; T-Bil, total bilirubin; ALP, alkaline phosphatase; T-cho, total cholesterol; Y-GTP, } \\
\text { gamma glutamyl transpeptidase; LDH, lactate dehydrogenase; Alb, albumin; Glb, globulin; ChE, } \\
\text { cholinesterase; AST, aspartate aminotransferase; ALT, alanine aminotransferase; Cr, creatinine; BUN, } \\
\text { blood urea nitrogen; CRP, C-reactive protein; Na, sodium; K, potassium; Cl, chloride; BGA, Blood Gas } \\
\text { Analysis; PaO2, partial pressure of arterial oxygen; PaCO2, partial pressure of arterial carbon dioxide; } \\
\text { BE, base excess; Lac, lactate }\end{array}$} \\
\hline
\end{tabular}

\section{Discussion}

In this case, a definite diagnosis of a yamakagashi bite could not be made. However, the patient had two bite wounds on the right lower leg, and the bleeding persisted 3 days after the injury, coagulopathy with fibrinogen levels $<50 \mathrm{mg} / \mathrm{dL}$ was present, and fibrinogen levels remained below detectable levels despite FFP administration. Therefore, the severe head injury caused by coagulopathy likely resulted from a yamakagashi bite. 
Yamakagashi is found throughout Russia and eastern Asia, including China, Taiwan, Korea, and Japan (excluding the Ryukyu region). ${ }^{2}$ They have two kinds of venom. ${ }^{3}$ Cervical gland venom is released from 10 pairs of glands under the skin of the neck when the neck is strongly compressed and the glands rupture, and it causes corneal ulceration and iritis when it enters the eye. Duvernoy's gland venom, in contrast, is released from the hind-region of the maxilla through conduit openings in front of the two pairs of fangs located on the back teeth of the maxilla. Because these fangs are short $(<2 \mathrm{~mm})$ and no muscles are needed to squeeze the Duvernoy's gland, a momentary bite is often not enough to release the venom. If back teeth are involved in the bite, this venom can enter the body and cause serious bleeding.

Yamakagashi venom is a prothrombin activator. It causes strong blood coagulation and has a weak thrombin-like effect, ${ }^{4}$ leading to disseminated intravascular coagulation (DIC) with a fibrinolytic phenotype. ${ }^{5}$ Disseminated fibrin formation occurs, and fibrinolysis is activated, causing hypofibrinogenemia and increased levels of fibrinogen degradation products. ${ }^{1}$

Therapies for DIC due to yamakagashi venom include serotherapy (definitive therapy) and recombinant thrombomodulin (rTM) therapy (alternative therapy). Yamakagashi antivenom can only be administered in clinical trials. Although Yamakagashi antivenom has an equine source, anaphylaxis rates are $0 \% .{ }^{6} \mathrm{In}$ one study, compared to the antivenom non-administered group $(n=15)$, the antivenom administered group $(n=19)$ had a better prognosis $(p=0.03)$ and lower incidence of renal failure requiring dialysis $(p=$ 0.03). ${ }^{1}$ Since Yamakagashi antivenom is used off-label in Japan, ${ }^{2}$ we need to participate in a clinical research group to use it. ${ }^{5}$

Additionally, considering that Yamakagashi venom causes DIC with a fibrinolytic phenotype, rTM preparations are expected to be effective, ${ }^{7}$ and their applications are being investigated. rTM can inhibit thrombin production, thus reducing bleeding symptoms and organ damage caused by DIC. ${ }^{8}$ However, rTM is contraindicated in the early phase of trauma because it may promote bleeding, and the patient in our case had an active intracranial hemorrhage. To our knowledge, there have been no reported cases of complications in cases of traumatic intracranial hemorrhage after yamakagashi bites due to rTM administration. Moreover, only one report of rTM use in the diagnosis of DIC due to trauma exists, and the efficacy of rTM has not been reported, ${ }^{9}$ although no life-threatening bleeding events have been observed in patients who die. Yamakagashi bites can cause DIC with a fibrinolytic phenotype; however, rTM may not be used in cases of yamakagashi bites with active bleeding due to trauma.

In this case, the possibility of a yamakagashi bite was not considered, and a large dose of FFP was administered to improve trauma-related severe coagulopathy. However, the intracranial hematoma worsened, with little improvement in fibrinogen levels, causing death. Even if we diagnosed the yamakagashi bite, owing to active bleeding caused by trauma, there would be no definitive treatment except yamakagashi antivenom.

\section{Conclusion}


In this case of a yamakagashi bite with active bleeding due to trauma, there could be no definitive treatment except for yamakagashi antivenom.

\section{Abbreviations}

CT

Computed tomography; FFP:Fresh frozen plasma; DIC:Disseminated intravascular coagulation;

rTM:Recombinant thrombomodulin;

\section{Declarations}

\section{Acknowledgments}

We acknowledge Editage (www.editage.com) for English language editing.

\section{Authors' contributions}

All authors were involved in the study manuscript. They have all read and approved the final manuscript.

\section{Funding}

There are no sources of funding.

\section{Availability of data and materials}

The datasets used and/or analyzed during the current study are available from the corresponding author on reasonable request.

\section{Ethics approval and consent to participate}

Not applicable

\section{Consent for publication}

Written informed consent was obtained from the patient's relative for publication of this case report and accompanying images.

\section{Competing interests}

The authors declare that they have no competing interests.

\section{References}

1. Hifumi T, Sakai A, Yamamoto A, et al. Effect of antivenom therapy of Rhabdophis tigrinus (Yamakagashi snake) bites. J. Intensive Care. 2014;2: 44. https://doi: 10.1186/s40560-014-0044-5. 
2. Morokuma K, Kobori N, Fukuda T, et al. Experimental manufacture of equine antivenom against Yamakagashi (Rhabdophis tigrinus). Jpn. J. Infect. Dis 2011; 64: 397-402.

https://www.niid.go.jp/niid/JJID/64/397.pdf

3. Ogawa $\mathrm{H}$, Ohmura $\mathrm{Y}$, Ohhashi $\mathrm{D}$, et al. A case of death due to snake (Rhabdophis tigrinus) bite and a review of similar case reports in Japan. J. Jpn. Surg. Assoc 1986; 47 (2): 250-3. https://www.jstage.jst.go.jp/article/ringe1963/47/2/47_2_250/_pdf/-char/ja

4. Komori K, Konishi M, Maruta Y, et al. Characterization of a novel metalloproteinase in Duvernoy's gland of Rhabdophis tigrinus tigrinus. J. Toxicol. Sci 2006; 31: 157-68. https://doi: 10.2131/jts.31.157.

5. Hifumi T, Murakawa M, Sakai A, et al. 2015. Potentially fatal coagulopathy secondary to Yamakagashi (Rhabdophis tigrinus) bites that completely recovered with antivenom treatment. Acute Med. Surg 2015; 2: 123-6. https://doi: 10.1002/ams2.69. eCollection 2015 Apr.

6. Hifumi T, Sakai A, Kondo Y, et al. Venomous snake bites: clinical diagnosis and treatment. J. Intensive Care. 2015; 3: 16. https://doi: 10.1186/s40560-015-0081-8.eCollection 2015.

7. Yamakawa $\mathrm{K}$, Aihara $\mathrm{M}$, Ogura $\mathrm{H}$, et al. Recombinant human soluble thrombomodulin in severe sepsis: a systematic review and meta-analysis. J. Thromb. Haemost. 2015; 13: 508-19. https://doi: 10.1111/jth.12841.Epub 2015 Mar 5.

8. Saito H, Maruyama I, Shimazaki S, et al. Efficacy and safety of recombinant human soluble thrombomodulin (ART-123) in disseminated intravascular coagulation: results of a phase III, randomized, double-blind clinical trial. J. Thromb. Haemost 2007; 5: 31-41. https://doi: 10.1111/j.1538-7836.2006.02267.x.Epub 2006 Oct 13.

9. Asai $Y$, Yamamoto $T$, Kito $D$, et al. Factors influencing the effectiveness of recombinant human soluble thrombomodulin on disseminated intravascular coagulation: a retrospective study. J. Pharm. Health Care. Sci. 2020; 2; 6(1): 26. https://doi: 10.1186/s40780-020-00183-7.

\section{Figures}




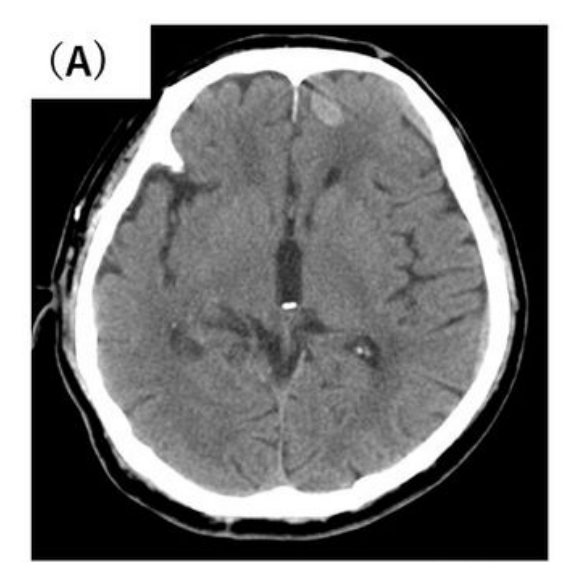

FFP

(2 unit)
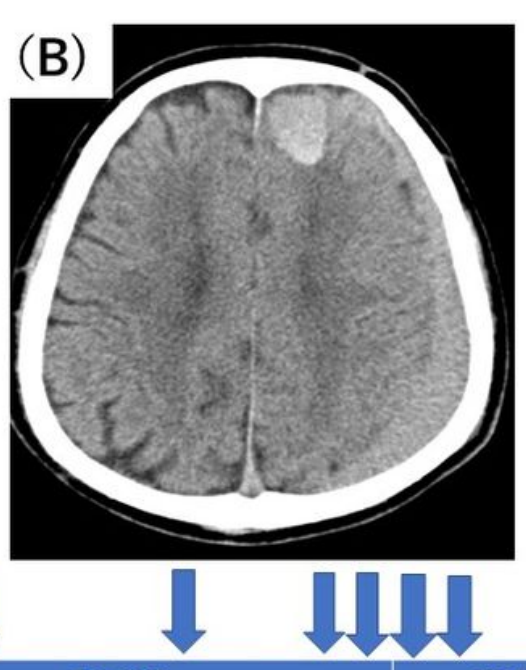

\begin{tabular}{|c|c|}
\hline & $11: 0$ \\
\hline PIt $\left(10^{3} / \mu \mathrm{I}\right)$ & 11.0 \\
\hline PT-INR & 2.12 \\
\hline APTT(sec) & $>100$ \\
\hline Fib(mg/dL) & $<50$ \\
\hline
\end{tabular}

9:00

11:00

13:00

\section{2:30}

18:00

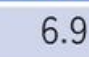

2.87

$>100$

$<50$

15:00

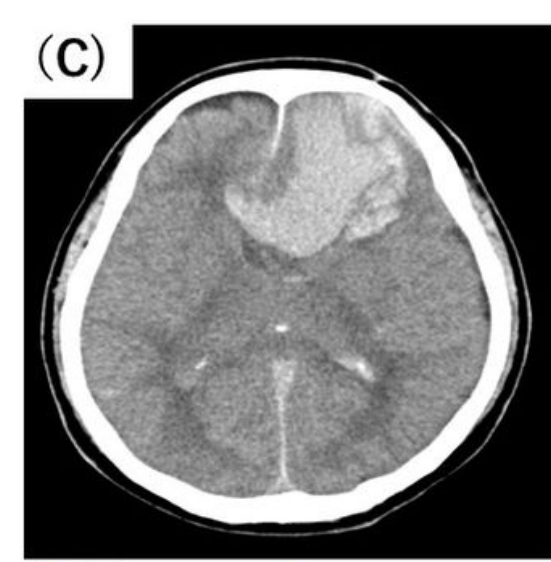

Death

\section{Figure 1}

The clinical course of intracranial lesions and coagulopathy in head Computed Tomography (CT) FFP, fresh frozen plasma; Plt, Platelet; PT-INR, Prothrombin Time-International Normalized Ratio; APTT, activated partial thromboplastin time; Fib, Fibrinogen $\triangle A \otimes H e a d ~ C T$ immediately after the injury showed cerebral contusion in the left frontal lobe and a left subacute subdural hematoma (performed at previous hospital). $\varangle \mathrm{B} \otimes T$ wo hours after the injury, the left subacute subdural hematoma was not significantly changed, but the brain contusion worsened. $\mathbb{C} \otimes$ Seven hours after the injury, the hematoma in the left frontal lobe was markedly enlarged and had perforated into the ventricle. When FFP administration was started, PT-INR and APTT showed a transient improvement, but Fib remained almost below the detection limit. 


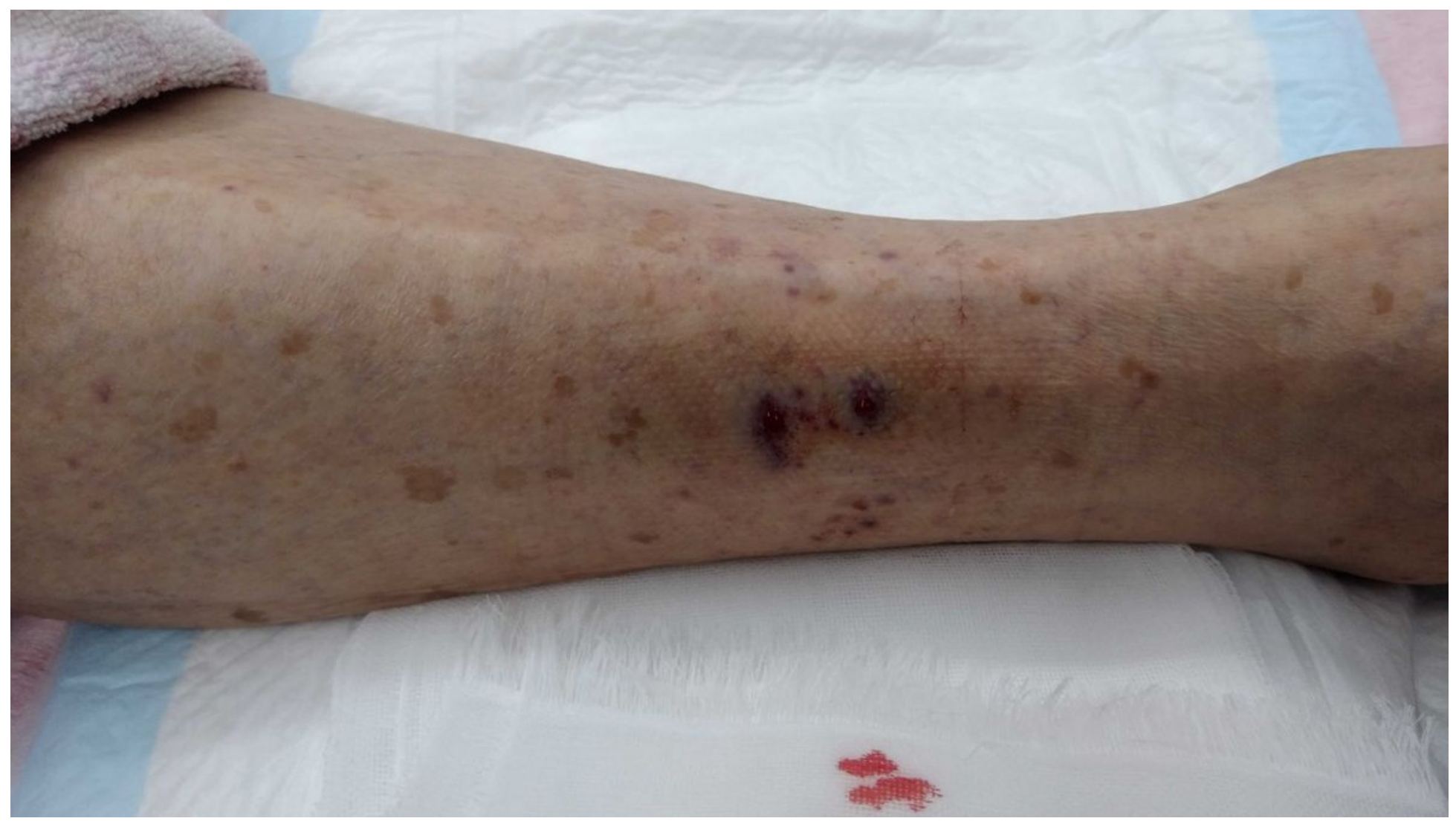

\section{Figure 2}

The patient's right lower leg Two bite wounds of few millimeters on the patient's right lower leg are observed. The wound showed persistent bleeding and swelling even though it was several days before the injury. 